Newsletter - Section on Classification, Diagnostic Assessment and

Nomenclature

19 May 2003

Resenhado por: Mário Eduardo Costa Pereira

\title{
Simpósio da Associação Mundial de Psiquiatria e da OMS discute em Nova Iorque os fundamentos filosóficos e metodológicos do diagnóstico em psiquiatria
}

A Seção de Classificação da Associação Mundial de Psiquiatria (AMP), em colaboração com o Escritório de Classificação da OMS e o International Center for Mental Health of the Mount Sinai School of Medicine, New York University, organizou em Nova York, nos dias 3 e 4 de maio pp. o Symposium on Philosophical and Methodological Foundations of Psychiatric Diagnosis.

Esse importante acontecimento científico ocorreu em continuidade com o processo de colaboração entre a AMP e a OMS no sentido do desenvolvimento de um sistema integrado internacional de classificação e de diagnóstico. Esse processo inclui uma enquete internacional sobre o uso da CID-10, do DSM-IV e de sistemas diagnósticos a eles relacionados (1999-2001), bem como dois outros simpósios anteriores, realizados em Londres (2001) e em Yokohama (2002), sobre os Sistemas Diagnósticos Internacionais. Além disso, duas publicações mais importantes documentaram os desenvolvimentos conceituais recentes e os achados empíricos que substanciam a necessidade do aperfeiçoamento dos sistemas internacionais de diagnóstico e classificação: um número duplo especial 
R E V I S T A

LATINOAMERICANA

DE PSICOPATOLOGIA

F U N D A M E T T L

ano $\mathrm{VI}$, n. 2, jun/ 2003

de Psychopathology (março-junho 2002) sobre Classificação e Diagnóstico Internacional: Experiência Crítica e Direções Futuras e a publicação dos Elementos Essenciais das Diretrizes Internacionais da AMP para a Avaliação de Diagnósticos (IGDA) (British Journal of Psychiatry, Suplemento de maio de 2003).

O simpósio de Nova Iorque reuniu importantes especialistas internacionais - filósofos, psiquiatras e outros cientistas da área da saúde - que trataram do complexo objeto da psiquiatria, bem como da decisiva questão do diagnóstico psiquiátrico.

O número aqui comentado da Newsletter da Seção de Classificação da AMP apresenta o programa, os resumos das intervenções e, sobretudo, as conclusões desse simpósio que são abaixo reproduzidas.

Deve-se atentar para inclusão de, para além de um diagnóstico baseado em evidências, uma perspectiva diagnóstica baseada em valores, contemplando a complexidade e a dimensão de ciências humanas própria à psiquiatria.

\section{Conclusões do Simpósio sobre os Fundamentos Filosóficos e Metodológicos do Diagnóstico Psiquiátrico}

1. Este simpósio faz parte de um processo colaborativo entre a Associação Mundial de Psiquiatria (AMP) e a Organização Mundial da Saúde (OMS) visando a melhorar o sistema classificatório e diagnóstico internacional. Várias sociedades, membros da AMP como a Associação Psiquiátrica Americana, as Sociedades Psiquiátricas Chinesa, Cubana e Japonesa, a Federação Francesa de Psiquiatria, e a Associação Psiquiátrica Latino-Americana estavam representadas. Os pontos altos desse processo em curso incluem: a) Uma enquete internacional sobre o uso da CID-10, do DSM-IV e de sistemas diagnósticos a eles relacionados (1999-2001); b) O Simpósio de Londres (2001) e o Simpósio de Yokohama (2002) sobre os Sistemas Diagnósticos Internacionais; c) A publicação de um número duplo especial de Psychopathology (março-junho 2002) sobre Classificação e Diagnóstico Internacional: Experiência Crítica e Direções Futuras; d) A publicação dos Elementos Essenciais das Diretrizes Internacionais da AMP para Avaliação de Diagnósticos (IGDA) (British Journal of Psychiatry, Suplemento de maio 2003).

2. Era ponto pacífico que organizar um simpósio sobre as bases conceptuais, epistemológicas e metodológicas do diagnóstico psiquiátrico era essencial nessa fase inicial do processo delineado acima. Isto foi considerado importante uma vez que algumas questões cruciais em diagnóstico e classificação psiquiátricos envolvem, além da coleta de numerosos dados empíricos, análises e escolhas em termos de quadro conceptual. 
3. Todos concordaram que os quatro eixos principais que deveriam nortear o simpósio eram componentes cruciais de seu tema geral e representavam algumas das questões mais fundamentais para progredir nesse campo. Os quatro eixos principais foram: a) Bases Conceptuais dos Sistemas Diagnósticos; b) Experiência, Contexto e Processos Diagnósticos; c) Medição: Taxonomia e Escalonamento, e d) Desafios Epistemológicos Apresentados por Campos Relacionados com a Saúde.

4. Enquanto formulação e enquanto processo ou atividade, o diagnóstico é essencial nos cuidados clínicos, na pesquisa, na formação e na saúde pública. Entre suas principais metas estão fornecer fontes de informações para os cuidados clínicos e iniciar o relacionamento paciente-clínico. Para a saúde pública, o diagnóstico situacional é particularmente útil como fonte de informações para planejar os serviços e o desenvolvimento de políticas.

5. Os modelos diagnósticos que enfocam a saúde tanto doentia quanto positiva, e que envolvem o clínico, o paciente e sua família como participantes interativos, exigem uma arquitetura multinível para levar em conta a natureza complexa das condições clínicas de maneira abrangente. O modelo diagnóstico proposto nas Diretrizes Internacionais da AMP (WPA) para a Avaliação de Diagnósticos (IGDA), que combina formulações padronizadas e idiográficas, bem como, instrumentalmente, a Família de Classificações Internacionais (FIC) da OMS parecem ser pontos de partida úteis.

6. A conceituação da patologia para levar adequadamente em conta suas várias implicações e conseqüências deve considerar como quadros tanto as provas científicas quanto as avaliações baseadas em valores (value-based assessments). Os níveis de descrição da patologia podem ser fenomenológicos e etiológicos, mas todos deveriam ser explicitamente formulados.

7. A descrição completa do estado de saúde de um indivíduo deveria também incluir elementos positivos como funcionamento, forças pessoais, apoios sociais e qualidade de vida (bem-estar subjetivo). Sua avaliação sistemática por meio de campos separados pode ser formulada de modo multiaxial, para que a Família de Classificações Internacionais (FIC) da OMS possa ser útil.

8. Frente à complexidade dos distúrbios psiquiátricos, aos desafios colocados pela diversidade cultural e pelas significações pessoais, e à propensão documentada dos clínicos a usar protótipos e histórias individuais em seus trabalhos, é importante incorporar formulações idiográficas narrativas como ingredientes indispensáveis de afirmações diagnósticas úteis.

9. Tanto o mundo interno quanto externo, cujas preocupações afetam o cérebro, a mente e a sociedade, são informações preciosas sobre a experiência e para a avaliação da patologia e assuntos ligados à saúde. 
10. Para que a psiquiatria seja uma ciência humana, isto é, para que considere o leque completo de dados da experiência humana, precisamos desenvolver modos de incluir as características pessoais e os agenciamentos (agency). Isto significa prestar muita atenção a fatores subjetivos como sentimentos, significações e desejo (will).

11. A psicologia social e a etnografia clínica revelam claramente que a experiência de sintomas está inserida em sistemas interpretativos de significação. Os relatos de sintomas e de experiências patológicas dependem fortemente do contexto de narração. Portanto, os modelos diagnósticos precisam prestar atenção a esses sistemas interpretativos de significações na avaliação das doenças clínicas. Os quadros culturais deveriam ser investigados minuciosamente tanto em saúde geral como em áreas particulares de patologia.

12. A boa ciência, as boas políticas públicas, e a boa política deveriam sempre ser consideradas juntas ao se elaborar boas classificações diagnósticas de distúrbios mentais.

13. A comorbidade é um desafio maior em nosologia psiquiátrica e pode ser um resultado da presença real de mais de um distúrbio num mesmo paciente ou um resultado artificial de nossas práticas diagnósticas. É preciso desenvolver modos de lidar efetivamente com este desafio.

14. Os modelos descritivos multivariados, quer sejam dimensionais, de gradeof-membership, ou outros, estão ficando cada vez mais interessantes para o diagnóstico psiquiátrico.

15. O papel da genética e da genômica em psiquiatria é cada vez mais importante e coloca novos desafios em classificação e diagnóstico psiquiátricos. Os conceitos de fenótipos neurobiológicos e comportamentais, assim como os de modificadores e precipitantes ambientais estão sendo claramente reconhecidos.

16. Os desafios epistemológicos apresentados pelas ciências psicológicas (psicodinâmica, processos cognitivos, e aprendizagem) podem ser considerados no quadro de trabalho psicoterapêutico (com uma atenção particular para os conflitos intrapsíquicos e interpessoais). Os pontos importantes a se tratar incluem: a) o contraste entre os modelos médicos e os modelos de crise; b) a metodologia aplicável para coletar informações sobre os distúrbios, e c) a estabilidade do diagnóstico.

17. As teorias de diagnóstico e prática psiquiátricos são social e culturalmente fundamentadas. Uma teoria psiquiátrica integrativa sobre diagnóstico que aspire a uma relevância internacional deve considerar as tradições de saúde e medicina das maiores civilizações. 
18. Os sistemas diagnósticos atuais, como a CID-10 e o DSM-IV, que consistem de conjuntos de critérios explícitos, contribuíram para melhorar a confiabilidade da avaliação diagnóstica em psiquiatria. Contudo, um número de questões que dizem respeito à validade de muitas das entidades diagnósticas incluídas nestas classificações permanecem problemáticas. Novas pesquisas conceptuais e empíricas são necessárias para sanar essas questões, e a noção de validade, tal como aplicada nas entidades diagnósticas em psiquiatria, pode precisar ser complementada com medidas da utilidade clínica dessas entidades.

19. O processo diagnóstico em psiquiatria deve respeitar e servir toda a pessoa do paciente que se apresenta para cuidados por meio de um entendimento e uma descrição abrangentes da doença clínica que exige uma intervenção. Paralelamente com o interesse emergente pela medicina personalizada em curso de desenvolvimento, o diagnóstico deve também ser útil para a prevenção e a promoção da saúde.

20. Desenvolver um sistema aplicável em nível internacional para uma avaliação abrangente do estado de saúde requer: a) envolver nisto provas científicas bem como experiência e sabedoria; b) testar a validade e a confiabilidade das propostas emergentes; c) planejar antecipadamente a implementação do sistema diagnóstico resultante e monitorar seu uso e sua utilidade; d) envolver um imenso leque de pesquisadores e clínicos do mundo inteiro; e) a contribuição dos representantes dos vários setores envolvidos (stakeholders) na saúde (clínicos, pacientes, famílias, educadores, pesquisadores, planejadores políticos, indústria etc.), e f) uma parceria entre a OMS e organizações profissionais-chave que representam numerosos países e disciplinas de saúde. 
Baruch, G. \& Fearon, P. “The evaluation of mental health outcome at a community-based psychodynamic psychotherapy service for young people: A 12month follow-up based on self-report data" Psychology and Psychotherapy: Theory, Research and Practice (2002), 75, 261-78 Resenhado por: Maria Carolina Ciotola Bruno

\section{Avaliação de acompanhamento de doze meses de pacientes submetidos à psicoterapia psicodinâmica ambulatorial}

Nos últimos anos tem-se notado dentro das discussões psicanalíticas alguns diferentes movimentos no sentido da abertura de espaço para pesquisas e discussões a respeito da demonstração da eficácia e efetividade de sua prática.

As opiniões divergem, pois, de um lado, grande parte da comunidade psicanalítica sempre manteve uma enorme distância de pesquisas deste tipo, pois entendem que, como a psicanálise tem como principal matéria-prima a subjetividade e que é uma prática que trabalha principalmente no domínio intrapsíquico, não há conciliação entre um trabalho tão subjetivo e pesquisas objetivas. Por outro lado, a psicanálise tem sido fortemente cobrada, tanto pelo mundo científico quanto pela opinião pública, para que haja um maior engajamento de sua parte nessas pesquisas de caráter mais empírico, e que, por meio destas, possa demonstrar os resultados de seu trabalho, para um mundo que não só o psicanalítico.

Esse artigo traz uma pesquisa nestes moldes, onde seus autores tentam criar dispositivos com o objetivo de avaliação de seu serviço.

A pesquisa é desenvolvida em uma instituição de Londres - The Brandon Centre for Counselling and Psychoterapy for Young People - que oferece a jovens entre 12 e 25 anos um trabalho em Psicoterapia Psicanalítica. O trabalho é desenvolvido por 16 psicólogos, todos tendo a psicanálise como referencial teórico. 
A pesquisa focaliza, portanto, a avaliação dos resultados obtidos junto a um grupo de 151 jovens que passaram por psicoterapia pela primeira vez e que foram acompanhados durante um ano.

Para os autores, fortes razões vêm sendo colocadas por diversos estudos em psicoterapia (e também em psicanálise) para que se desenvolvam pesquisas deste tipo, razões estas que eles entendem como bastante relevantes também dentro de seu serviço, que é desenvolvido em um contexto clínico específico (diferente dos tradicionais consultórios privados - onde não seria viável a realização de pesquisas deste tipo), levando-os, assim, à adoção rotineira e sistemática de avaliações da efetividade de seu trabalho em psicoterapia psicanalítica.

As principais razões apontadas pelos autores para a necessidade desta pesquisa foram:

1. A maioria dos estudos de avaliação de efetividade em psicoterapia, principalmente das ditas "tradicionais" (como é o caso da psicoterapia psicanalítica) falham em demonstrar resultados favoráveis;

2. A psicoterapia psicanalítica, por sua especificidade clínica, é em geral pobremente apoiada em evidências empíricas;

3. Pesquisadores têm mostrado que as perspectivas clínicas, quando baseadas em coletas de dados não sistematizadas e em uma análise informal destes, são freqüentemente métodos incertos de se fazer julgamento do progresso do tratamento;

4. Há uma crescente necessidade de demonstração da efetividade dos serviços de psicoterapia dentro das instituições;

5. Há um desejo de identificar qual grupo de jovens é efetivamente beneficiado e qual grupo não se beneficia pelo serviço oferecido.

Esta pesquisa também teve o intuito de colher dados para que, por meio deles, os autores pudessem refletir sobre alguns pontos que eles elegeram como fundamentais ao bom andamento de seu trabalho institucional, e para que possam, por esta avaliação, fazer as mudanças e melhorias necessárias dentro do serviço. Os principais pontos colocados foram:

- Quais seriam os efeitos do trabalho de psicoterapia levando-se em conta a duração (que pelo contexto institucional é curta e limitada) e a quantidade e tipo de mudanças alcançadas pelo paciente?

- Quais os aspectos que poderiam estar associados ou não a essas mudanças? Será que as características demográficas (sexo, idade, escolaridade) desses pacientes influenciam no resultado terapêutico? E os sintomas presentes? E os fatores específicos associados ao trabalho dentro da instituição?

Sabemos que o problema metodológico é uma das principais dificuldades a serem enfrentadas por essas pesquisas, pois envolve contradições de difícil contorno e uma necessidade de adaptar e/ou criar novos dispositivos que melhor 
se encaixem nos moldes das psicoterapias, (ainda mais das ditas psicanalíticas), que, no caso específico dessa pesquisa, escolheu-se uma amostra de 151 jovens que nunca tinham feito psicoterapia antes. Foram feitas reavaliações periódicas, logo na sua entrada, em 3 meses, em 6 meses, e em um ano de trabalho.

Os dados foram todos coletados pelos psicoterapeutas em suas entrevistas iniciais e foram divididos em:

- Dados demográficos (idade, sexo, escolaridade, lugar de residência, alguns dados parentais, profissão, situação conjugal, indicações) e

- Dados clínicos (incluindo o diagnóstico, que foram baseados no CID-10, e foi selecionado um principal diagnóstico, mesmo sabendo da complexidade diagnóstica de alguns casos).

- Dados coletados através de duas escalas de sintomas (Global Assessment of Functioning Scale - GAF; Severity of Psychosocial Stressors for Children and Adolescentes - SPS).

- Ainda foi selecionada por cada psicoterapeuta a principal queixa do paciente (relatada pelos pacientes nas entrevistas iniciais), e se essas foram mudando ou não com o tempo.

Os dados foram coletados em quatro diferentes momentos do trabalho e seus resultados divididos em três categorias (sendo que os pontos mais problemáticos elegidos pelos pesquisadores foram divididos em problemas “internos", problemas “externos" e problemas "gerais”):

1. As mudanças principais: onde traçaram um retrato geral das mudanças desses pontos problemáticos com o passar do tempo;

2. O número de mudanças de status clínico para não-clínico;

3. Uma categorização de casos de acordo com a presença estatística de mudanças nestes jovens.

A pesquisa detectou durante o trabalho com os pacientes importantes modificações em todas as três categorias. Para os autores, a pesquisa foi muito importante à medida que detectou os benefícios gerais do trabalho do serviço de psicoterapia psicanalítica junto aos jovens, onde houve resultados mais favoráveis ainda nos problemas chamados, por eles, de "internos".

$\mathrm{O}$ artigo termina discutindo como os resultados de um monitoramento sistemático de efetividade em psicoterapia psicanalítica vêm formando uma base empírica que tem, assim, melhor direcionado as mudanças de seu serviço, otimizando a cada dia mais a ajuda a esses jovens.

Claramente existem inúmeros problemas, tanto de ordem metodológica quanto de ordem teórica, que não foram bem discutidos nesta pesquisa, mas a pergunta que fica é: será que porque os problemas são de difícil resolução não vale a pena nem pensar sobre eles? Será que a psicanálise não tem sido ela própria a maior prejudicada ao abster-se dessa discussão? 